\title{
Integration of a Dual GPS and ISM Antenna PIFA in a Human Body Patch for Elderly Tracking
}

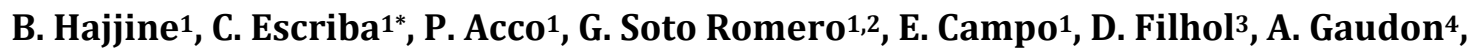 \\ L. Bories ${ }^{5}$, J. Y. Fourniols ${ }^{1}$
}

${ }^{1}$ LAAS-CNRS, Université de Toulouse, CNRS, INSA, UT2J, Toulouse, France

${ }^{2}$ ISIFC-Génie Biomédical, Université de Franche Comté, Besançon, France

${ }^{3}$ Telecom Design Company, Canéjan, France

${ }^{4}$ SIGFOX Company, Labège, France

${ }^{5}$ Pôle de médecine et spécialités médicales, Centre Hospitalier du Val d'Ariège, Foix, France

Email: *cescriba@laas.fr

Received 9 April 2016; accepted 14 June 2016; published 17 June 2016

Copyright (C) 2016 by authors and Scientific Research Publishing Inc.

This work is licensed under the Creative Commons Attribution-NonCommercial International License (CC BY-NC).

http://creativecommons.org/licenses/by-nc/4.0/

(c) (i) (8) Open Access

\section{Abstract}

This paper introduces the development of two Printed Inverted F Antennas (PIFA) to be integrated in a patch worn on the back of human body. This study is part of SACHA project (Search And Computerize Human Acts) whose main aim is to design a tracking device for monitoring the elderly suffering from Alzheimer disease. The first antenna frequency is $868 \mathrm{MHz}$ and will be used to communicate with a specific SIGFOX communication technology. A second frequency $(1575.42$ MHz) is used for GPS geolocation. The proposed development is a part of research in Human Health Monitoring field, based on the monitoring of the behavior, the location and the position of the patient, and could deeply help the medical team or family to instantly respond through a warning generation.

\section{Keywords}

Alzheimer, PIFA, Patch, GPS, Tracking, Falls, Elderly

\section{Introduction}

Monitoring frail or dependent people is a real challenge in a nowadays-ageing world. The age remains among ${ }^{*}$ Corresponding author.

How to cite this paper: Hajjine, B., Escriba, C., Acco, P., Soto Romero, G., Campo, E., Filhol, D., Gaudon, A., Bories, L. and Fourniols, J.Y. (2016) Integration of a Dual GPS and ISM Antenna PIFA in a Human Body Patch for Elderly Tracking. Open Journal of Antennas and Propagation, 4, 34-45. http://dx.doi.org/10.4236/ojapr.2016.42004 
the main factors causing and facilitating the development of Alzheimer disease that affects $5 \%$ of persons aged more than 65 years and $15 \%$ of those older than 85 years. Every year the situation becomes more and more severe as the recorded number of new cases of persons suffering from this dementia increases by 160,000 only in France. This number was estimated at 860,000 in 2007 and according to the National Institute for Statistics and Economic Studies, it could increase to 1.3 million before 2020. At the world level, 25 million persons suffer from Alzheimer disease, of which $60 \%$ have troubles of orientation and wandering; this number could pass to 42 million in 2020 and 81 million in 2040 [1]. Among drawbacks of this pathology, fugues constitute a very serious issue: be lost in streets and forget where we live end generally in a tragic way. So these dependent and fragile people need a continuous assistance and monitoring. Instead of hospitalization or institutionalization, one proposed solution is to assist them 24 hours a day thanks to well-designed "smart" devices, which can monitor and analyze patient activity. In this objective, the development of a geolocation system able to give the exact geographical coordinates of the person who carries it and able to send an alert is essential in case of fugues, dangers, overtaking of a safety zone or other kind of unusual behaviors. These systems are generally based on the use of GPS and exist in the form of watches, telephones and even shoes [2]-[5]. These devices even if they are non-invasive require the patient to put it on and wear it without removing it throughout the day. This paper describes the development of two Printed Inverted F Antennas (PIFA) integrated in a tracking patch for elderly monitoring. After an overview of the existing solutions for elderly monitoring in Section 2, the patch SACHA is presented in the third section. Antennas are described in the fourth, fifth and sixth parts.

\section{Overview of Systems Dedicated to Elderly Monitoring}

The monitoring of elderly has known a surge of interest recently and new trends and recent developments in communication technology and sensors have emerged. These developments have provided the opportunity to design novel wired or wireless systems. These systems are able to monitor and classify the activities of elderly as well as to detect dangerous situations such as falls or fugues in the case of Alzheimer disease. Among the various devices we can distinguish four categories.

\subsection{Smart Homes}

These systems are based on the use of various sensors integrated in the residence of the monitored person to follow his activities $24 \mathrm{~h} / 24$. Different kind of sensors can be used: cameras, infrared sensors, magnetic switches, pressure sensors... Using cameras for instance allows distinguishing various activities: walking, cooking, eating, etc and to notice the slightest change in the habits of the supervised person. This technique detects also dangerous situations such as falls which really threaten elderly life: this is performed for example by the calculation of the speed of the head that witnesses a large movement during a fall [6] [7].

\subsection{Wearable Systems}

These devices are developed in the aim to be carried by the helped person anytime and anywhere. They exist in different forms: bracelets, pendants, watches... The portability of this kind of systems involves several criteria of conception that must deal with size, weight, shape, autonomy, simplicity, efficiency...

Wearable systems can be divided in three types according to the data treatment methods: data processor, data logger and data forwarder [8].

Data processor category is characterized by the presence of a data processing unit that allows to bring back information from sensors to different activities analysis and to detect anomalies.

The data loggers [9] have also the advantage to monitor various activities whatever the location of the helped person. Here, if an abnormal event took place, it will be detectable only after the upload and treatment of collected data by a computer.

In data forwarders, a transmitter system is added using various technology of communication: RF, Bluetooth Low Energy... for the transmission of information coming from sensors [10].

\subsection{In Vivo Systems}

These systems require a surgery to integrate them into the human body with the purpose of monitoring of some physiological parameters such as blood pressure [11] or cardiac activities [12]. 
Another type takes the form of a capsule or a pill that the patient can swallow for the monitoring of the medication adherence for example [13].

\subsection{Heterogeneous Systems}

This method aims to combine both Smart Home integrated systems and wearable systems to benefit from their advantages and so to increase the efficiency of the whole system [14]-[16].

\section{Patch SACHA}

In the following, we introduce the patch SACHA, dedicated to the surveillance of elderly suffering from Alzheimer disease [17]. Our ambition is to develop a non-intrusive system in the form of an electronic patch to ensure falls detection and geolocation. The specific location of this device between the scapulae limits the wrenching or forgetting to wear problem for people with advanced Alzheimer's disease phases. The development of the patch SACHA is thought to be invisible and non-invasive in the elderly's everyday life in order to avoid any disturbances or discomfort. Our device is equipped with two antennas (868 MHz and GPS) whose design is described in this paper and a miniaturized printed coil for wireless charging. The patch SACHA is compact and can ensure a permanently functioning of 13 hours in fugues situations (activation of the GPS geolocation). Besides, the normal charging period is 3 days with a wireless charging time of 4 - 5 hours. The adoption of this technique is due to our desire to ensure easy use of the patch in addition to a waterproof feature via a suitable packaging for continuous control even in the shower where the probability of an accidental fall is higher.

This smart device triggers alarms in the case of anomalies such as falls, detects fugues thanks to the integration of GPS geolocation function and communicates with SIGFOX network for data transfer [18] (Figure 1).

Designed to be stuck on the skin, the patch SACHA has several features that help to ensure a permanent control on the patient activities:

1) Falls detection: this function is ensured by the use of an accelerometer that measures the acceleration components in the three space dimensions. Falls are detected by comparing them with predefined characteristic thresholds.

2) Living area: this property is provided by a keep alive communication between the patch and a RF beacon that determines a security perimeter whose exceeding is detected by the rupture of this link.

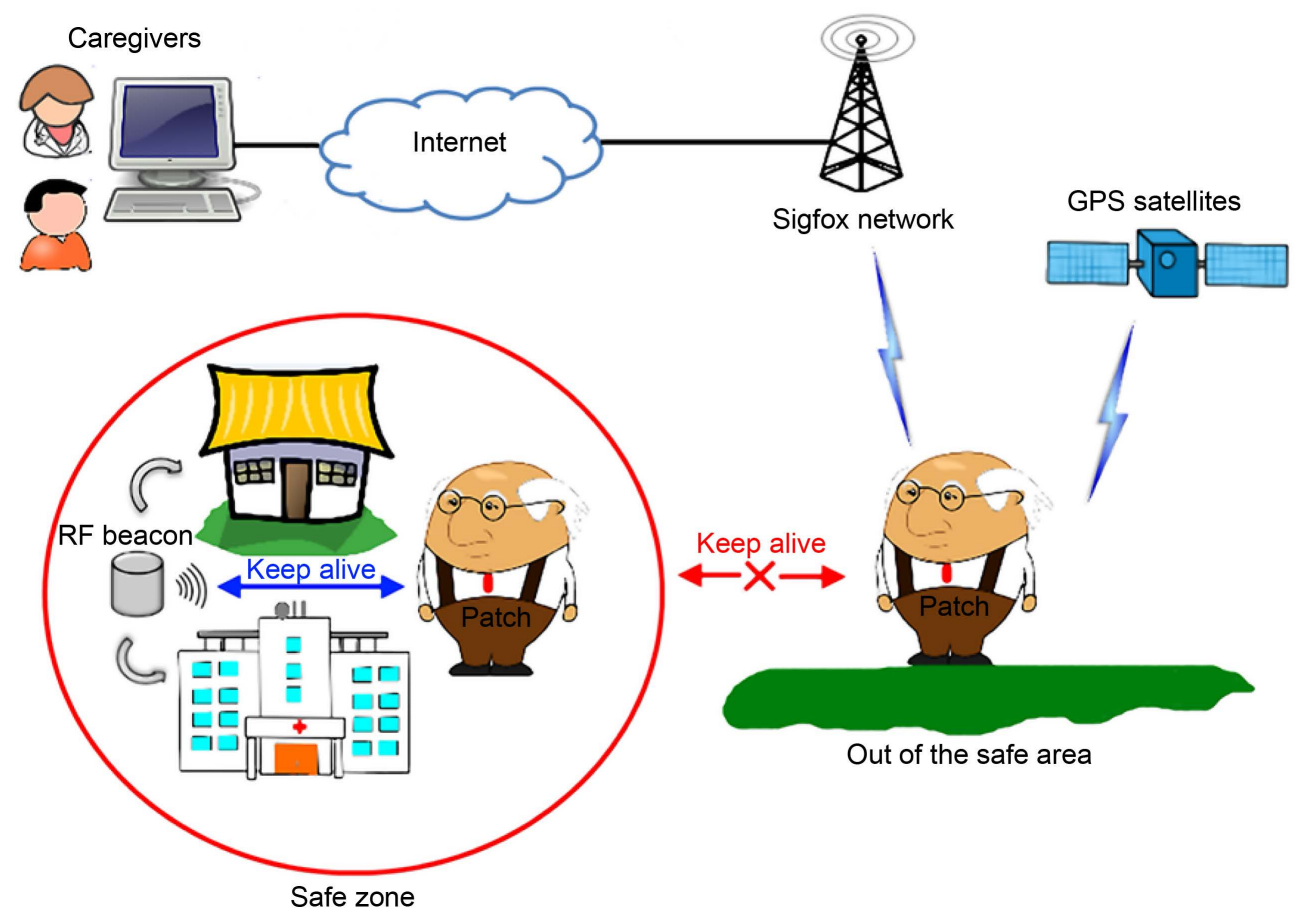

Figure 1. Patch SACHA principle. 
3) Geolocation: the tracking is activated in the case of fugues detected by the leaving of the safe zone in a non-permitted period. This property requires the use of a specific receiver and an antenna to communicate with GPS satellites.

4) Data transmission: the patch has the ability to communicate with SIGFOX stations to transmit data and alarms.

\section{Development of an ISM (Industrial Scientific and Medical) Printed Inverted F Antenna}

Printed Inverted F Antenna is characterized by a compact structure that provides an ease of integration into the communication equipment. Its name comes from its shape that looks like an inverted F (Figure 2).

The power supply is placed between the ground plane and the radiating arm whose length must be equal to the quarter of wavelength $(\mathrm{L}=\lambda / 4)$ and shorted to the ground plane via a line $\mathrm{H}$.

For frequencies of hundreds of megahertz, the radiating arm becomes more cumbersome: $8.64 \mathrm{~cm}$ for 868 $\mathrm{MHz}$ for example. In that case, there is a necessity to reduce the size of the integrated antennas: This can be done by folding the radiating arm as a meanders shape [19]-[21] (Figure 3). 4).

Another method is based on the addition of a capacitive or inductive load after the feeding point [22] (Figure

Some research works can be referenced for the design and the development of printed inverted $\mathrm{F}$ antennas that work in the $868 \mathrm{MHz}$ ISM band [23]-[25] and GPS [26]-[28]. The IFA ground plane has an important role to determine the efficiency of the antenna. It should be at least as high as the quarter of the wavelength $(\lambda / 4)$ and at

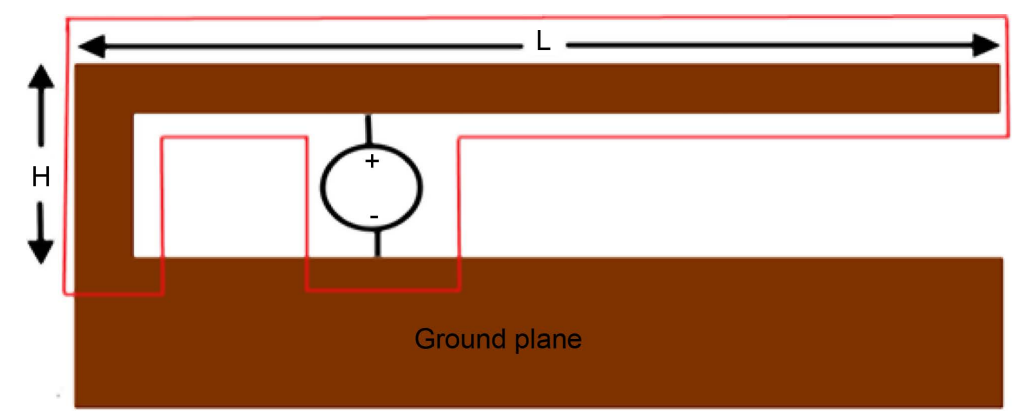

Figure 2. Inverted $\mathrm{F}$ antenna where the radiating arm is long of $\mathrm{L}$, and separated from the ground plane by a line long of $\mathrm{H}$.
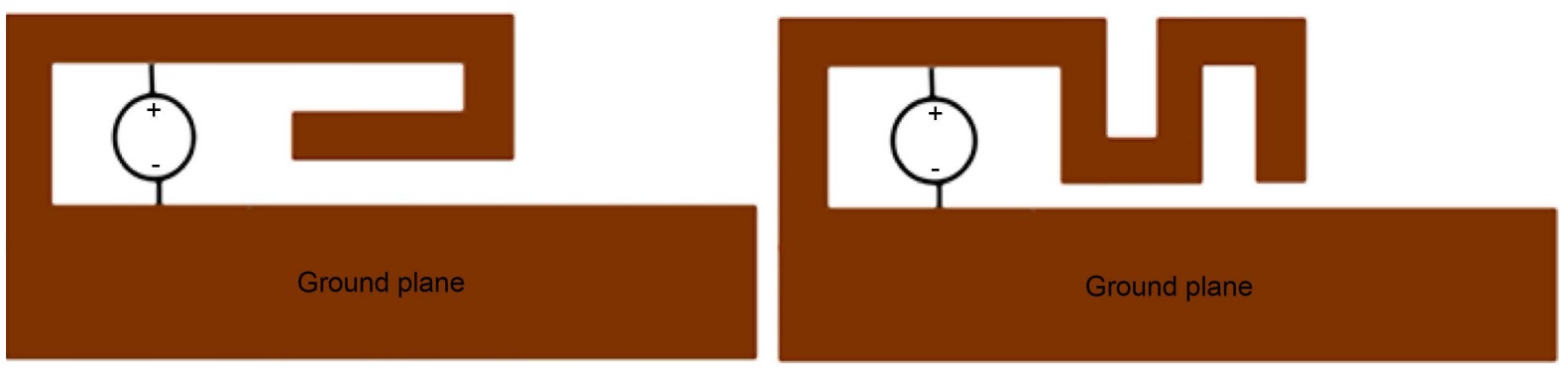

Figure 3. PIFA miniaturization.

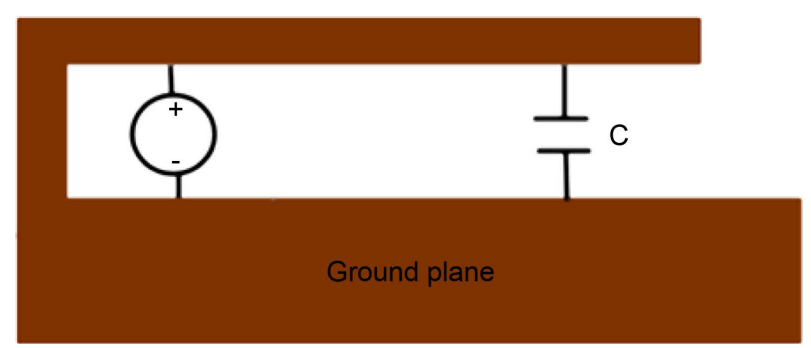

Figure 4. PIFA with a capacitive load. 
least as wide as the IFA length. Choosing smaller dimensions decrease the antenna performances. For our patch, the miniaturization is a very important factor and the ground plan and antennas dimensions are chosen to be the smallest possible to ensure both high integration and acceptable functioning.

The patch SACHA is equipped with a microcontroller, a GPS module, an accelerometer, a transceiver and two antennas. The first antenna is used to communicate with the GPS satellites $(1575.42 \mathrm{MHz})$ for the recovery of the geographical coordinates of the person who carries the patch, and the second antenna has an operational frequency of $868 \mathrm{MHz}$ and ensures the communication with SIGFOX stations network. All these components and functionalities have been integrated in the first prototype whose the size is $53.5 \times 17 \mathrm{~mm}^{2}$. This small size enables to place it directly on the human body as a discrete device to be rapidly forgotten by the patient (Figure 5).

As the frequency radio link is $868 \mathrm{MHz}$, the radiating arm of the PIFA must have a length of $8.64 \mathrm{~cm}$. With the criterion to reduce the size of the patch, the radiating arm was 5 times folded while spreading its rest at a distance of $0.5 \mathrm{~mm}$ of the ground plan.

This antenna was designed on the top layer of a six layers PCB: used substrate is FR4 $(\mathcal{E} r=4.6)$, metal copper thickness is $35 \mu \mathrm{m}$, and distance between layers is $120 \mu \mathrm{m}$.

Before the fabrication process of the patch PCB, a simulation of the proposed antenna was carried out. This phase permits to validate the performances of the proposed design, to study the influence of the variation of some parameters such as the ground plane, the meanders forms and the metal substrate types and thicknesses. The RF software used for simulation is ADS (Advanced Design System).

As we can see from the Figure 6, the antenna is composed of a $0.25 \mathrm{~mm}$ width line to ensure a characteristic impedance of $50 \Omega$. This line is extended up to the end of the antenna to avoid discontinuities of the track. Several simulations were carried out to reach the optimal performances.

Simulation results show a good reflection coefficient $\mathrm{S}_{11}=-40 \mathrm{~dB}$ with a bandwidth of $6.5 \mathrm{MHz}$ and a gain of $-7 \mathrm{dBi}$ (Figure 7).

The 3D and 2D plots of the normalized radiation pattern at $868 \mathrm{MHz}$ are presented in Figure 8 and Figure 9.
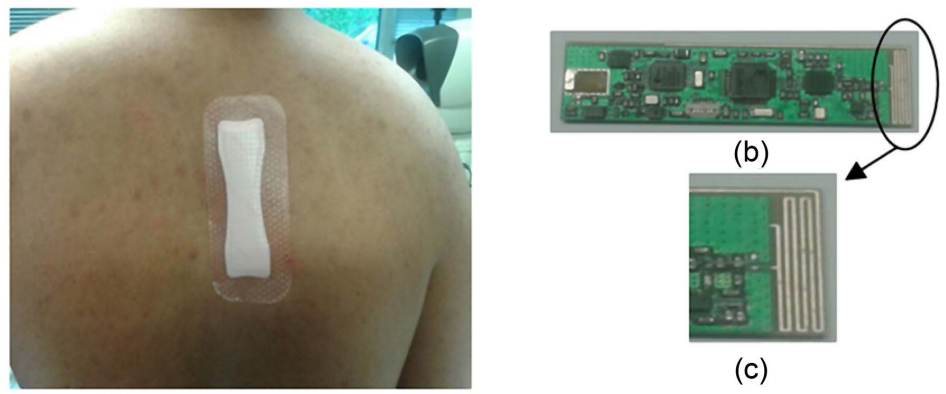

(a)

(c)

Figure 5. (a) Tracking patch glued to a user back; (b) Overview of the first prototype of the patch; (c) Zoom on the ISM antenna.

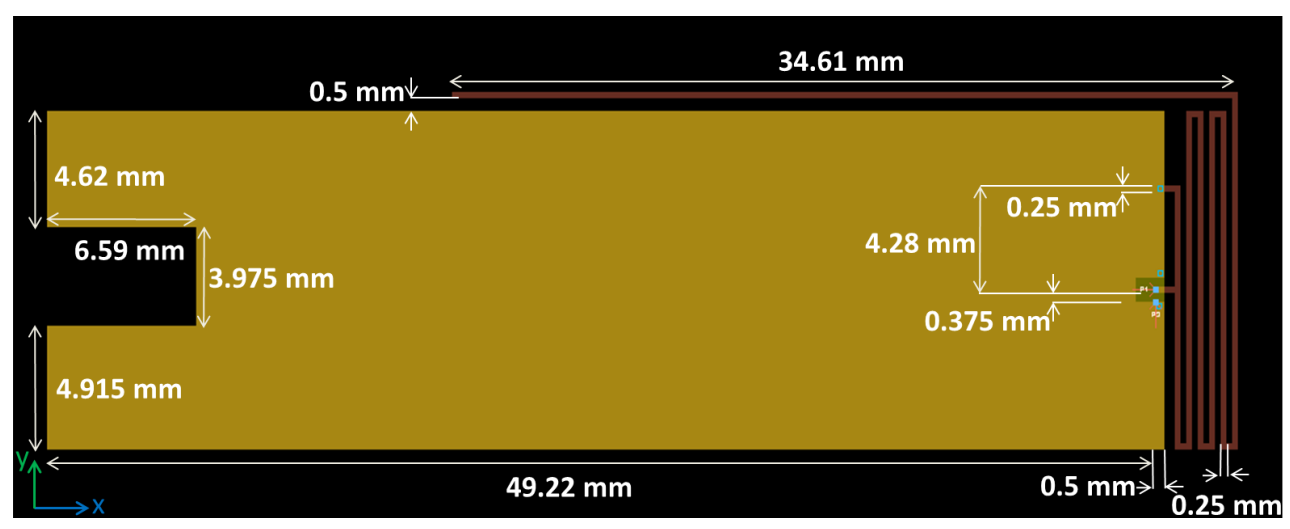

Figure 6. PIFA momentum ADS simulation. 


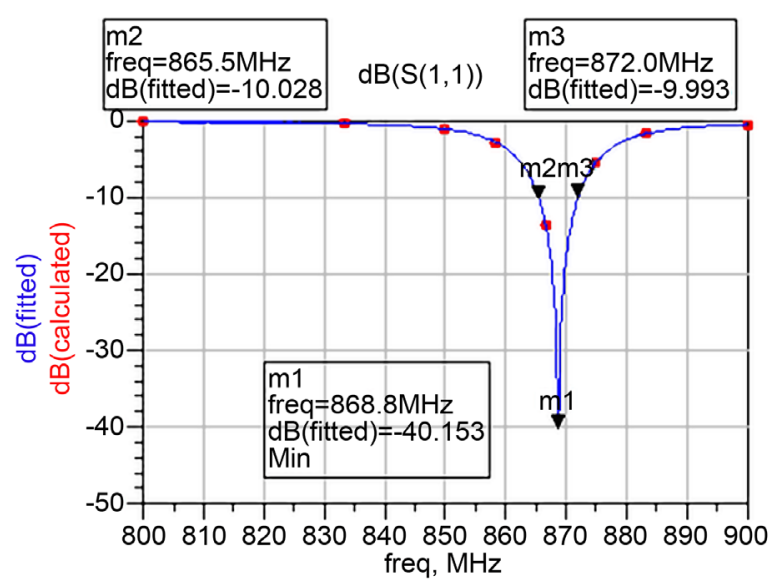

Figure 7. ISM antenna $S_{11}$ reflection coefficient.

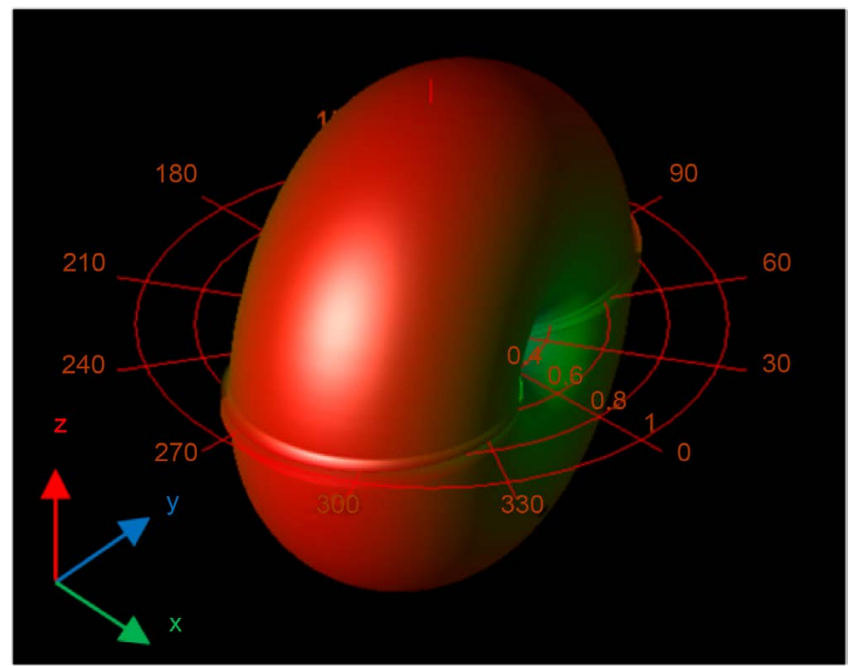

Figure 8. ISM antenna 3D normalized radiation patter.
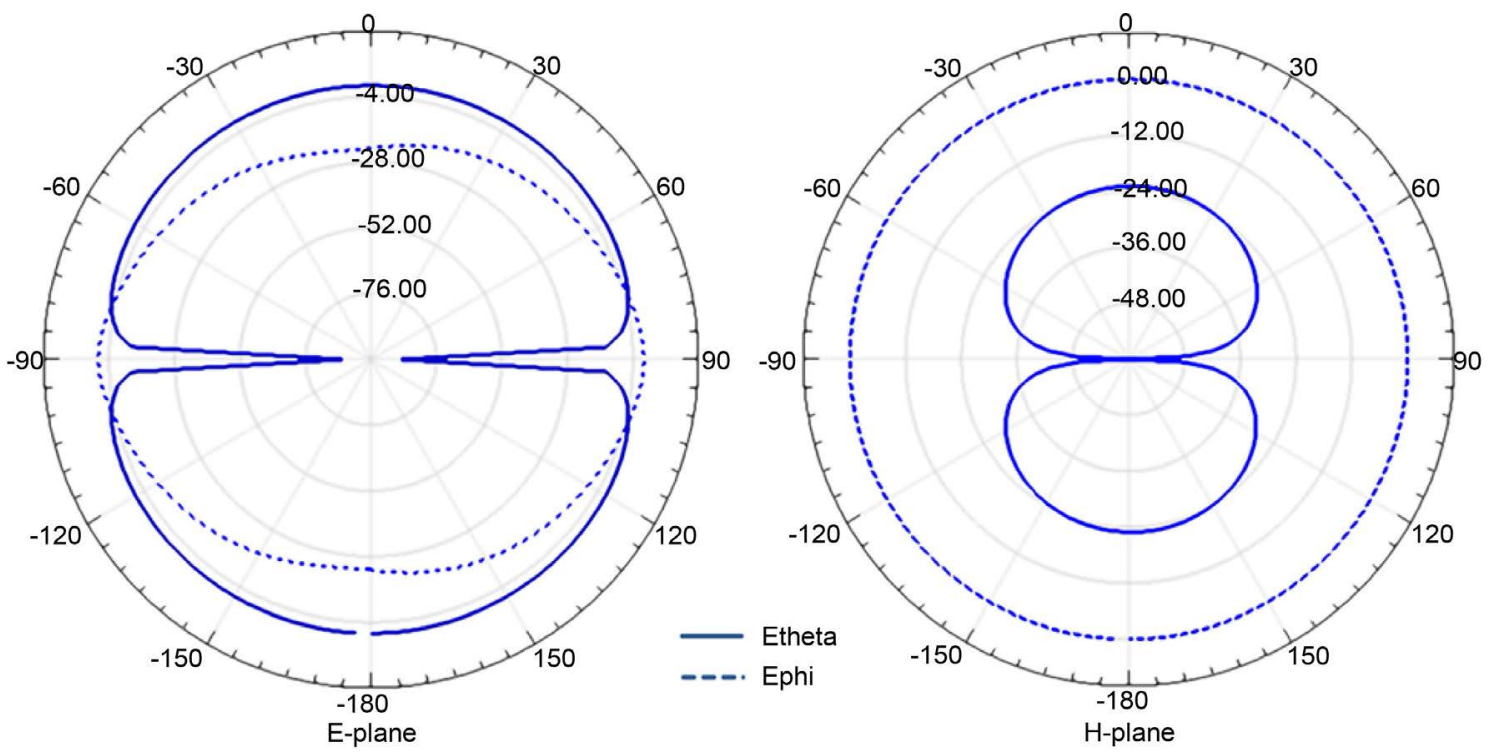

Figure 9. Normalized radiation pattern components Etheta and Ephi in E and $\mathrm{H}$ plane. 
For the 3D plot, the ISM antenna is included in the X-Y plane. The red color indicates intense radiation compared to the green parts: the radiation intensity is reduced in the plane of the FR4 substrate.

After this optimization phase, the functional validation of the antenna is powered through matching process using a vector network analyzer (VNA) to obtain $\mathrm{S}_{11}$ reflection coefficient (Figure 10).

Measurement results allow to assume a quite good reflection coefficient $S_{11}=-30.8 \mathrm{~dB}$ with a bandwidth of $15 \mathrm{MHz}$.

Tests in real case were carried out by choosing 56 points in different places around the Laboratory for Analysis and Architecture of Systems (LAAS-CNRS) in Toulouse, France (Figure 11). From each point 10 frames were sent and compared to the total number of frames received by the different SIGFOX stations.

For this test, among 56 points, only three were not seen by the Sigfox network. For the other points, the RF link is kept with different numbers of the received frames (Table 1).

As the tracking patch must present a good functioning in the case of falls in order to transmit properly the alarm, another test was carried out to validate its ability to keep the connection with the Sigfox network even in the worst case of falls represented by a fall on the back (Figure 12). In that case, the patch is located under the
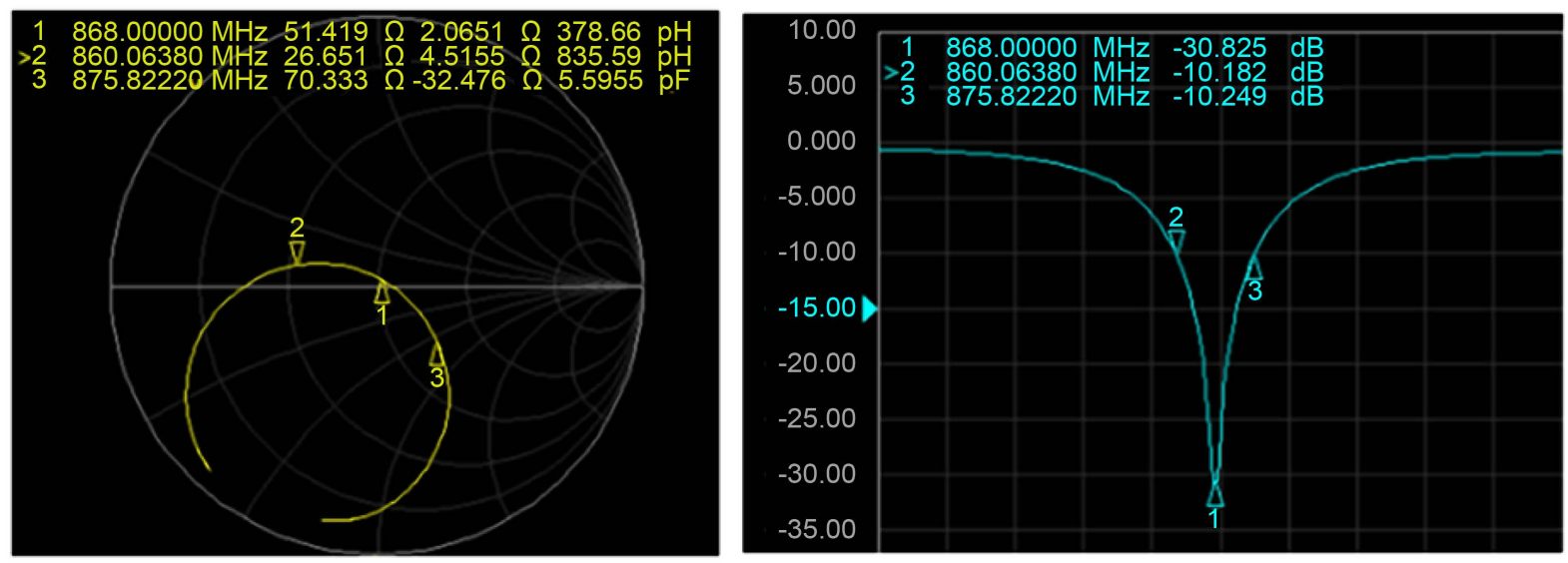

Figure 10. $\mathrm{S}_{11}$ measurement.

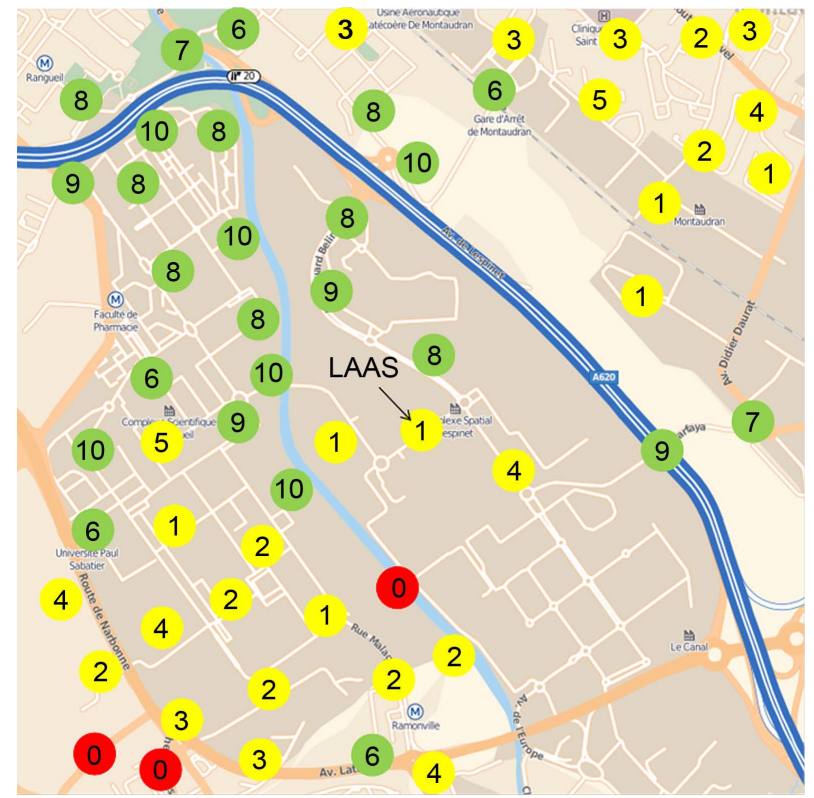

Figure 11. Results of ISM PIFA tests for the 56 measuring points around the LAAS-CNRS. Given numbers correspond to received signals compared to initially 10 sent frames. Green dots correspond to reception for a ratio of $>50 \%$, yellow dots to occurrence between $10 \%$ and $40 \%$ and red dots are used when no signal has been received. 
Table 1. Reception quality.

\begin{tabular}{cc}
\hline Received frames & Total rate \\
\hline 0 & $5.35 \%$ \\
$\leq 5$ & $50 \%$ \\
$>5$ & $44.65 \%$ \\
\hline
\end{tabular}

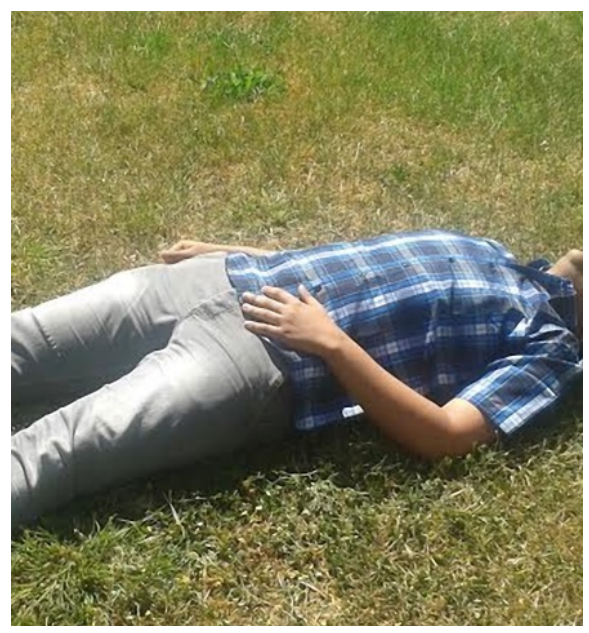

Figure 12. RF link test in the case of a fall on the back.

human body and the antennas performances can be influenced by the human tissue besides the ground effect.

Unlike the previous tests, this one is based on the selection of a single point at which 10 frames were sent from four different postures that represent the possible cases after a fall. Results are given in Table 2.

The Table 2 shows that the RF link with the Sigfox network ensured by the ISM $868 \mathrm{MHz}$ antenna is kept in the different falls postures. In the unfavorable case we lose only two frames among the ten sent (lying on the left side). In the other cases including the fall on the back only a single frame is lost.

The results of these tests validate the performances of our patch and prove its ability to ensure a good control even in the presence of the human body and the ground effect.

\section{GPS Antenna Design}

To obtain geolocation after fugue detection, we provide a GPS tracking powered through specific algorithm linked with Sigfox radio keep alive communication.

The GPS antenna is also a PIFA whose performances have been validated by simulation using ADS software. This tool allows studying the mutual influence and coupling of the two antennas in order to reach the best results. A wireless charger system was also added to the patch to ensure an ease of use and waterproof characteristic [29].

Figure 13 presents the design of the second version of the patch SACHA with ADS software taking into account all new PCB modifications and also the prototype of the tracking patch inserted in a plastic packaging to ensure waterproof characteristic.

The packaged patch has a greater dimension compared to the first version described in this paper. This is due to the integration of the wireless charging functionality that is not ensured in the previous patch. This new dimension of $5.8 \times 2.6 \mathrm{~cm}^{2}$ still remains small and not disturbing when the patch is glued between the shoulder blades.

The GPS antenna is characterized by a quite good reflection coefficient (Figure 14): simulated $\mathrm{S}_{22}=-44 \mathrm{~dB}$ $(\mathrm{BW}=25 \mathrm{MHz})$ and measured $\mathrm{S}_{22}=-20 \mathrm{~dB}(\mathrm{BW}=39 \mathrm{MHz})$.

This GPS antenna has a simulated gain of $0.56 \mathrm{dBi}$.

This antenna provides approximately the same plot of the radiation pattern as the ISM one as can be observed on Figure 15. The radiation intensity is reduced at the substrate plane (Figure 16). 
Table 2. Second test results.

\begin{tabular}{cc}
\hline Position & Received frames \\
\hline Lying on the back & 9 \\
Lying on the stomach & 9 \\
Lying on the right side & 9 \\
Lying on the left side & 8 \\
\hline
\end{tabular}

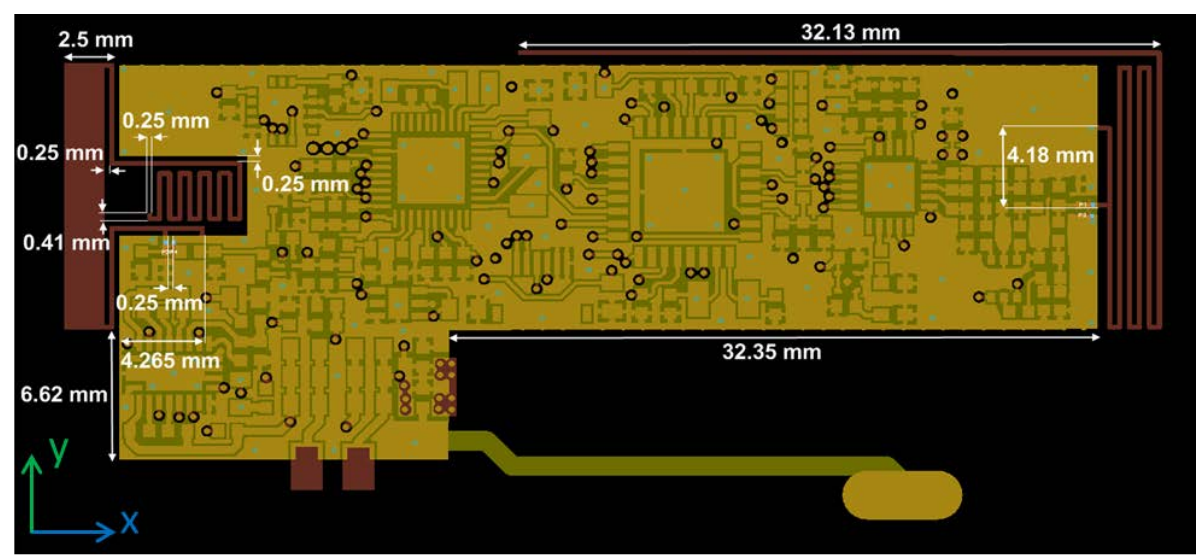

(a)

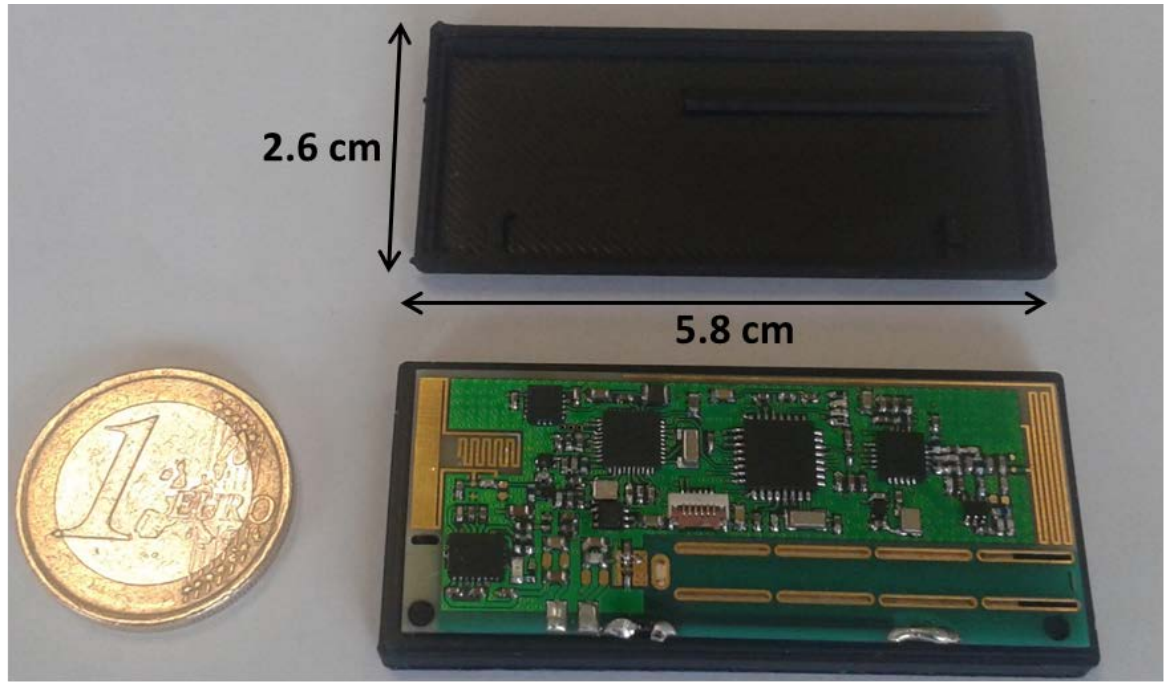

(b)

Figure 13. (a) ADS antennas design; (b) Patch SACHA with packaging.

\section{Antennas Coupling: ISM PIFA Performance Shift}

Taking into account GPS antenna proximity, ISM antenna $S_{11}$ reflection coefficient was shifted. This result implied small modifications (length of the radiating arm and the distance between the shorted and feeding point) to obtain the optimum performances and to validate the $868 \mathrm{MHz}$ antenna design near the GPS one as presented in Figure 17: simulated $S_{11}=-42 \mathrm{~dB}(\mathrm{BW}=7 \mathrm{MHz})$ and measured $\mathrm{S}_{11}=-16 \mathrm{~dB}(\mathrm{BW}=16.2 \mathrm{MHz})$. The simulated gain is $-7 \mathrm{dBi}$.

\section{Conclusion and Future Works}

This paper presents an optimized design PIFA at $868 \mathrm{MHz}$ and GPS integrated in a tracking patch for persons 

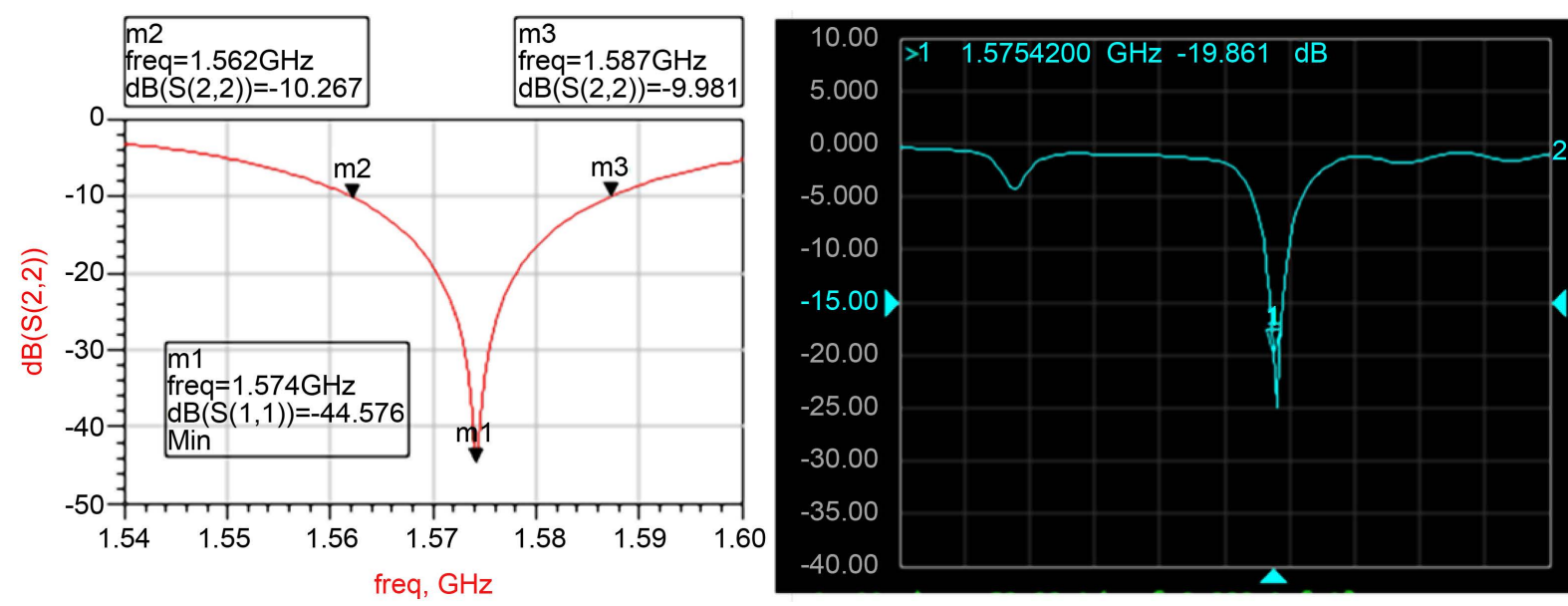

Figure 14. Simulated and measured $\mathrm{S}_{22}$ of the GPS antenna.

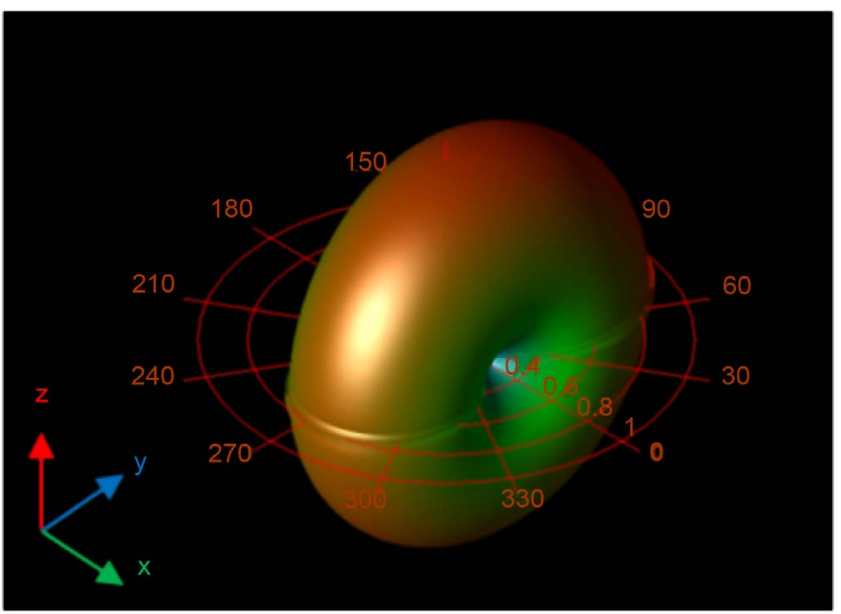

Figure 15. 3D normalized radiation pattern of the GPS antenna.
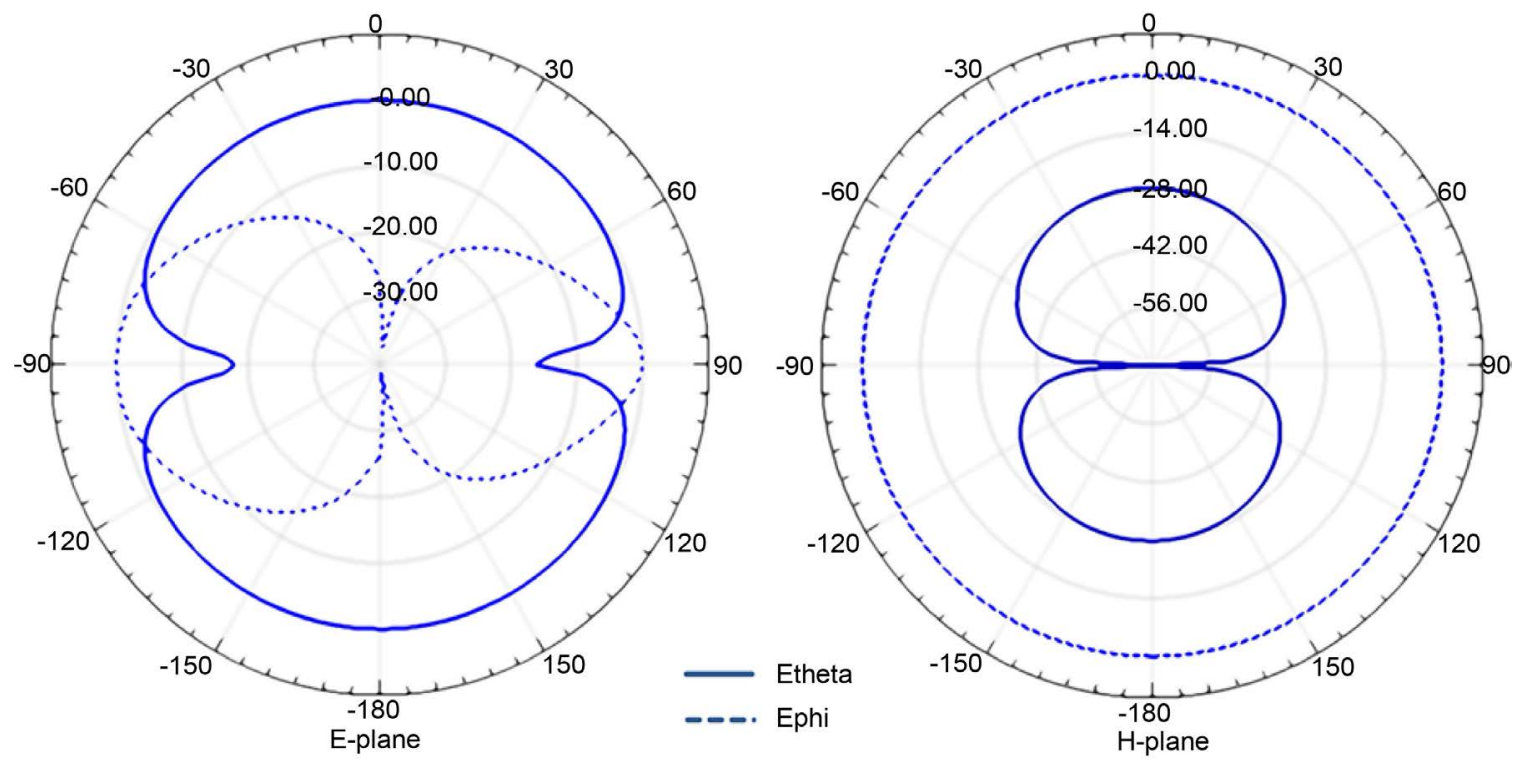

Figure 16. Normalized radiation pattern components Etheta and Ephi in E and H plane. 

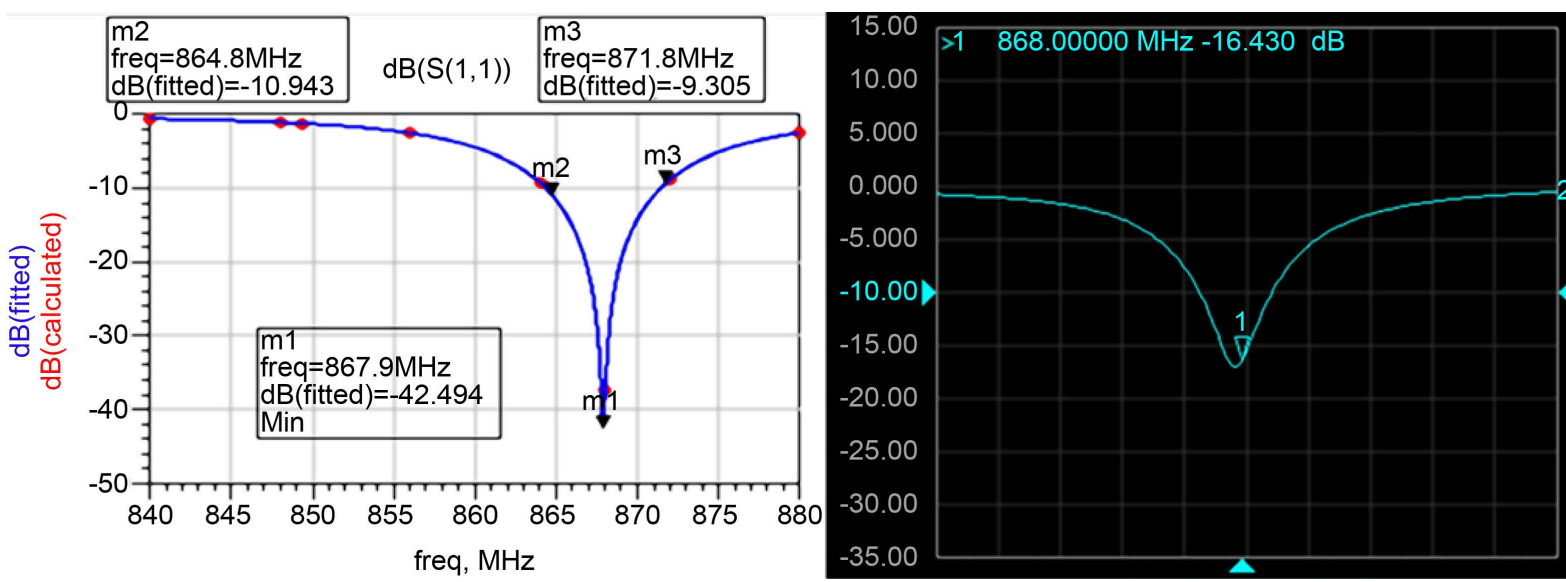

Figure 17. Simulated and measured $\mathrm{S}_{11}$ of the ISM antenna with the presence of the GPS PIFA.

affected by Alzheimer disease. In the proposed methodology design, the mutual influence and coupling are taken into account in the development. The developed patch highlights that antennas keep good performances when they are tested in real life conditions and particularly when they are glued on the skin between the shoulder blades. Finally we were able to develop a tracking device, with good integrated antennas: ISM $\mathrm{S}_{11}=-16 \mathrm{~dB}$ and GPS $S_{22}=-20 \mathrm{~dB}$. These PIFA were designed using the patch PCB to reduce the total cost of the tracking system and ensure a high degree of integration.

\section{Acknowledgements}

This work is part of project SACHA funded by French government and “Région Midi Pyrénées” in France. The partners of the project are Sigfox, Axible and Telecom Design companies, e-santé and CHIVA hospital.

\section{References}

[1] d'Alzheimer, M. (2016) Tout savoir sur la maladie d'Alzheimer. http://www.maladiedalzheimer.com/statistiques-alzheimer.html

[2] PradeepRajan, T. and Jayashree, C. (2013) Virtual Security Zones for Student Tracking and Elderly Fall Alert Basedon GPS Watch and Skin Pressure Sensitive Lock. International Journal of Scientific Engineering and Technology, 2, 145148.

[3] Calvo-Palomino, R., de lasHeras-Quiros, P., Santos-Cadenas, J.A., Roman-Lopez, R. and Izquierdo-Cortazar, D. (2009) Outdoors Monitoring of Elderly People Assisted by Compass, GPS and Mobile Social Network. Proceedings of the 10th International Work-Conference on Artificial Neural Networks: Part II: Distributed Computing, Artificial Intelligence, Bioinformatics, Soft Computing, and Ambient Assisted Living, Salamanca, 10-12 June 2009, 808-811. http://dx.doi.org/10.1007/978-3-642-02481-8_122

[4] Paiva, S. and Abreu, C. (2012) Low Cost GPS Tracking for the Elderly and Alzheimer Patients. Procedia Technology, 5, 793-802. http://dx.doi.org/10.1016/j.protcy.2012.09.088

[5] GPS Shoe (2016). http://www.gpsshoe.com/

[6] Khawandi, S., Daya, B. and Chauvet, P. (2011) Implementation of an Intelligent Surveillance System for Elderly. Journal of Theoretical and Applied Information Technology, 34, 65-70.

[7] Rougier, C., Meunier, J., St-Arnaud, A. and Rousseau, J. (2006) Monocular 3D Head Tracking to Detect Falls of Elderly People. 28th Annual International Conference of the IEEE Engineering in Medicine and Biology Society, New York, 30 August 2006-3 September 2006, 6384-6387. http://dx.doi.org/10.1109/IEMBS.2006.260829

[8] Ni Scanaill, C., Carew, S., Barralon, P., Noury, N., Lyons, D. and Lyons, G.M. (2006) A Review of Approaches to Mobility Telemonitoring of the Elderly in Their Living Environment. Annals of Biomedical Engineering, 34, 547-563. http://dx.doi.org/10.1109/IEMBS.2006.260829

[9] Tung, J.Y., FL Semple, J., Woo, W.X., Hsu, W.-S., Sinn, M., Roy, E.A. and Poupart, P. (2011) VALMA: Voice, Activity, and Location Monitoring for Alzheimer's Disease and Related Dementias. RESNA/ICTA 2011: Advancing Rehabilitation Technologies for an Aging Society, Toronto, 5-8 June 2011. 
[10] Song, K.-T. and Wang, Y.-Q. (2005) Remote Activity Monitoring of the Elderly Using Two-Axis Accelerometer. Proceedings of 2005 CACS Automatic Control Conference, Tainan, 18-19 November 2005.

[11] Potkay, J.A. (2008) Long Term, Implantable Blood Pressure Monitoring Systems. Biomedical Microdevices, 10, 379392. http://dx.doi.org/10.1007/s10544-007-9146-3

[12] Reveal LINQ ICM System (2016). http://www.medtronicdiagnostics.com/us/cardiac-monitors/reveal-linq/index.htm

[13] Hafezi, H., Robertson, T.L., Moon, G.D., Au-Yeung, K.-Y., Zdeblick, M.J. and Savage, G.M. (2015) An Ingestible Sensor for Measuring Medication Adherence. IEEE Transactions on Biomedical Engineering, 62, 99-109. http://dx.doi.org/10.1109/TBME.2014.2341272

[14] Charlon , Y., Bourennane, W., Bettahar, F. and Campo, E. (2013) Activity Monitoring System for Elderly in a Context of Smart Home. IRBM, Digital Technologies for Healthcare, 34, 60-63. http://dx.doi.org/10.1109/TBME.2014.2341272

[15] Atallah, L., Lo, B., Yang, G.-Z. and Siegemund, F. (2008) Wirelessly Accessible Sensor Populations (WASP) for Elderly Care Monitoring. Second International Conference on Pervasive Computing Technologies for Healthcare. Pervasive Health, Tampere, 30 January-1 February 2008, 2-7.

[16] Crispim-Junior, C.F., Joumier, V., Hsu, Y.-L., Pai, M.-C., Chung, P.-C., Dechamps, A., Robert, P. and Bremon, F. (2012) Alzheimer's Patient Activity Assessment Using Different Sensors. Gerontechnology, 11, 266-267. http://dx.doi.org/10.4017/gt.2012.11.02.597.00

[17] Hajjine, B., Escriba, C., Campo, E., Zedek, S., Acco, P., Soto Romero, G., Hemeryck, A. and Fourniols, J.Y. (2015) Development of an Electronic Patch for Falls Detection and Elderly Tracking. Proceedings of the International Conference on Biomedical and Health Informatics (ICBHI), Haikou, 9-10 October 2015.

[18] Sigfox. http://www.sigfox.com/fr/

[19] Chebihi, A., Le Thuc, P., Luxey, C. and Staraj, R. (2007) Conception d'antennes compactes pour petits objets communicants. 15ième Journées Nationales Microondes, Toulouse, 23-25 May 2007.

[20] Hossain, M.S., Karmokar, D.K. and Morshed, K.M. (2011) Compact Zigzag Inverted-F Antenna with Matching Network for Wi-Fi Operation in Portable Devices. International Journal of Soft Computing and Engineering (IJSCE), 1, 396-401.

[21] Noordin, N.H., Wong, Y.C., Erdogan, A.T., Flynn, B. and Arslan, T. (2012) Meandered Inverted-F Antenna for MIMO Mobile Devices. Antennas \& Propagation Conference (LAPC), Loughborough, 12-13 November 2012, 1-4. http://dx.doi.org/10.1109/lapc.2012.6402948

[22] Loizou, L., Buckley, J., Belcastro, M., Barton, J., O’Flynn, B. and O’Mathuna, C. (2013) Miniaturized Inverted-F Antenna with Capacitive Loading. 7th European Conference on Antennas and Propagation (EuCAP), Gothenburg, 8-12 April 2013, 3213-3216.

[23] Loizou, L., Buckley, J., O’Flynn, B., Barton, J., O’Mathuna, C. and Popovici, E. (2013) Design and Measurement of a Planar Dual-Band Antenna for the Tyndall Multiradio Wireless Sensing Platform. IEEE Sensors Applications Symposium (SAS), Galveston, 19-21 February 2013, 11-14. http://dx.doi.org/10.1109/sas.2013.6493548

[24] Loizou, L., Buckley, J. and O’Flynn, B. (2013) Design and Analysis of a Dual-Band Inverted-F Antenna with Orthogonal Frequency-Controlled Radiation Planes. IEEE Transactions on Antennas and Propagation, 61, 3946-3951. http://dx.doi.org/10.1109/TAP.2013.2260316

[25] Pynttari, V., Halonen, E., Sillanpaa, H., Mantysalo, M. and Makinen, R. (2012) RF Design for Inkjet Technology: Antenna Geometries and Layer Thickness Optimization. IEEE Antennas and Wireless Propagation Letters, 11, $188-191$. http://dx.doi.org/10.1109/LAWP.2012.2187269

[26] Devi, S.S. and Pradeepa, M. (2014) Microstrip Inverted F Antenna for GPS Application. International Journal on Recent and Innovation Trends in Computing and Communication, 2, 3143-3148.

[27] II Kim, J., Chong, Y.J. and Choi, J.I. (2003) Printed Multiband Terminal Antenna for Multiple Wireless Services. 12th International Conference on Antennas and Propagation (ICAP 2003), 1, 324-327.

[28] Li, Z. and Rahmat-Samii, Y. (2005) Optimization of PIFA-IFA Combination in Handset Antenna Designs. IEEE Transactions on Antennas and Propagation, 53, 1770-1778. http://dx.doi.org/10.1109/TAP.2005.846807

[29] Hajjine, B., Escriba, C., Charlot, S., Hemeryck, A., Roux, J., Zedek, S.F. and Fourniols, J.-Y. (2016) Development of a Printed Coil for Wirelessly Charging a Tracking Elderly Patch. Wireless Engineering and Technology, 7, 83-95. http://dx.doi.org/10.4236/wet.2016.72009 